\title{
Modeling and Field Measurements of Photovoltaic Units Connected to LV Grid. Study of Penetration Scenarios
}

\author{
Ioulia T. Papaioannou, Minas C. Alexiadis, Charis S. Demoulias, Member, IEEE, \\ Dimitris P. Labridis, Senior Member, IEEE, and Petros S. Dokopoulos
}

\begin{abstract}
The operation of photovoltaic (PV) units connected to the grid is characterized by several uncertainties due to the number of currently operating units, the points where these units are sited, the exported power, and the injection of harmonic currents. The objective of this paper is to investigate the impact of the penetration of PV units in the low-voltage $(\mathrm{LV})$ network. Thus, a model has been developed for the computation of load flows, harmonics, and voltages in the feeders. A PV panel is modeled as an irradiance-driven current generator, with an embodied maximum power point (MPP) tracking algorithm; it is connected to the network via electronic switches that represent the PV inverter. Simulations are performed with PSIM and Harmoniques simulator packages. Results from the simulated model are validated with data acquired from field measurements and bibliography. Finally, the acceptable penetration level of $P V$ systems is investigated for several scenarios, depending on the topology of the LV network, the number, size, and locations of loads and PV units.
\end{abstract}

Index Terms-Distributed energy sources, photovoltaic inverters, photovoltaic power systems, power system harmonics.

\section{INTRODUCTION}

$\mathbf{T}$ HE use of PV units is continuously increasing as a result of active government policies for renewable energy sources. Large penetration of domestic PV systems in urban sites is being planned and encouraged with subsidies, tax exemptions, and a social shift toward a more environmental friendly way of life. As long as PV systems were scattered along kilometers of countryside grid, their operation aroused no concern; yet, the present situation with a great number of PV units aggregated in residential areas brings skepticism in the academic community. The questioning of PV operation focuses on the following issues:

1) the acceptable penetration of PV units in the LV distribution network without exceeding voltage and harmonic limits, as defined in the EN 50160 [1] and IEEE 1547 standards [2];

2) the guideline which determines that PV inverters should operate at unity power factor is now under consideration [3]-[5]; since PV inverters operate as current sources, there

Manuscript received March 31, 2010; revised September 21, 2010; accepted October 23, 2010. Date of publication January 13, 2011; date of current version March 25, 2011. This work was supported by the EU IP Project EU-DEEP under Contract SES6-CT-2003-503516. Paper no. TPWRD-00235-2010.

The authors are with the Department of Electrical and Computer Engineering, Aristotle University of Thessaloniki, Thessaloniki 54124, Greece (e-mail: ioulia.papaioannou@ec.europa.eu).

Digital Object Identifier 10.1109/TPWRD.2010.2095888 is no control on the voltage at the point of common coupling (PCC), thus overvoltage problems may appear in certain cases.

Previous research has incorporated various models to simulate PV units, depending on the studied issues. In surveys concerning load flow, voltage levels, and power losses, PV units are confronted as $P-Q$ elements [6]-[10] with relevant PV generation patterns. On the other hand, studies on harmonic distortion use current sources with harmonic profile spectrums based on measured data, inverter configurations, or limits set by standards [11]-[15].

The performance of these models has been examined for connections to LV networks of various configurations, concerning size and siting of loads and PV units, length and width of distribution lines, as well as profile of load demand for urban or rural areas. Several conclusions have been derived from the aforementioned studies without, however, implying a general rule of permissible penetration level as follows.

- The density of installed PV power $\left(\mathrm{kW} / \mathrm{m}^{2}\right)$ is not a sufficient parameter to define the maximum power penetration since the capacity of the grid is not taken into account. In rural feeders, problems with overvoltage may occur, especially when PV capacity is aggregated at the end of the line [14]. This applies also in urban feeders in cases of high penetration or weak dimensioned lines [16] or due to inflexible voltage regulation control at the transformer [9].

- Permissible concentration levels are highly dependent on load demand, thus, for minimum loads, the PV capacity is limited, whereas for maximum demand, PV penetration may exceed the load [17].

- PV impact on voltage harmonic distortion $\left(\mathrm{THD}_{\mathrm{V}}\right)$ is minor; it should be studied along with background distortion and grid impedance. On the other hand, the current harmonic distortion $\left(\mathrm{THD}_{\mathrm{I}}\right)$ depends on the control mechanisms and filters of the PV system and may occasionally exceed the standards' limits [9] and [18]. The siting of PV systems also influences $\mathrm{THD}_{\mathrm{I}}$. In [11], $\mathrm{THD}_{\mathrm{I}}$ varies according to the topology (uniform, increasing and decreasing generation) of PV systems along the line.

Other scholars are focusing on the PV inverter mechanisms and subsystems (e.g., MPP trackers and control systems [19]-[25]), but within component-oriented analysis without expanding on integration issues.

Many power-quality (PQ) issues on feeders with $\mathrm{PV}$ units are actually related to PV conversion mechanisms and the princi- 
ples under which they operate. Thus, this paper proposes a realistic modeling of performance and operation of a PV system incorporating:

- the behavior of the PV panel as specified in its technical brochures;

- the equivalent electrical model of the PV cell;

- the MPP tracking process for the generation of maximum power under specified conditions of irradiance;

- the conversion mechanisms of the inverter, including a $\mathrm{dc}-\mathrm{dc}$ boost converter and a dc-ac converter for the final power injection to the grid;

- the appropriate control systems for power-quality assurance.

Using the aforementioned model, voltages and harmonic distortion can be calculated under various conditions of irradiance, load demand, and network configuration.

This paper is outlined in the following sections: Section II describes the PV model developed in the PSIM simulator package and, partly, in Visual $\mathrm{C}++$. In Section III, the operational behavior of the PV model is validated using field measurements in a $20-\mathrm{kWp}$ PV plant in Northern Greece and data acquired from published surveys. Finally, in Section IV, various PV penetration scenarios are investigated for different network configurations.

\section{PV PlANT MODEL}

A typical PV plant consists of PV modules connected in series to obtain the desired voltage; the individual strings are then connected in parallel to allow the system to produce more current. For each string, the operational voltage at the maximum power point (MPP) is calculated by multiplying respective values for one module with the total number of modules. In this respect, the MPP algorithm is developed for one panel and then, by defining the number of the panels forming the string, the system calculates the corresponding values of the voltage and power at MPP $\mathrm{V}_{\mathrm{MPP}}$ and $\mathrm{P}_{\mathrm{MPP}}$.

\section{A. Graphical Approach of MPP Using Technical Brochures}

In order to express the voltage and current at MPP ( $\mathrm{V}_{\mathrm{MPP}}$ and $\mathrm{I}_{\mathrm{MPP}}$, respectively), the open-circuit voltage $\left(\mathrm{V}_{\mathrm{oc}}\right)$, and shortcircuit current $\left(\mathrm{I}_{\mathrm{SC}}\right)$ as functions of irradiance $\mathrm{G}$, one should recur to the characteristic curves of the PV panel found in the technical brochures. Besides the I-V characteristic curve, the $\mathrm{V}_{\mathrm{oc}}-\mathrm{G}$ and the $\mathrm{I}_{\mathrm{sc}}-\mathrm{G}$ curves as well as normalized corrections for $\mathrm{V}_{\mathrm{oc}}$ and $\mathrm{I}_{\mathrm{sc}}$ depending on temperature $\mathrm{T}\left({ }^{\circ} \mathrm{C}\right)$ are usually provided. As an example, the commercially available PV module Sharp NU-SOE3E $180 \mathrm{~W}$ is used. Based on the curves provided (Fig. 1), the following equations can be extracted:

$$
\begin{aligned}
I_{s c} & =0.00837 G(\mathrm{~A}) . \\
V_{o c} & =0.004167 \cdot G+25.834(\mathrm{~V}) .
\end{aligned}
$$

Note: The linear (2) becomes less accurate for low values of irradiance $\mathrm{G}<300 \mathrm{~W} / \mathrm{m}^{2}$. The values of (1) and (2) are valid for a cell temperature of $25^{\circ} \mathrm{C}$. In case of different temperatures, the aforementioned values are slightly corrected based on the brochure's diagrams.
Characteristic curves: current / power vs. voltage (cell temperature: $25^{\circ} \mathrm{C}$ )

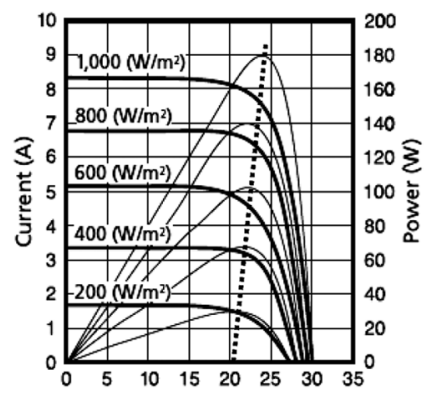

Voltage $(V)-$ Current vs. voltage - Power vs. voltage
Characteristic curves: open-circuit voltage/ short-circuit current vs. irradiation (cell temperature: $25^{\circ} \mathrm{C}$ )

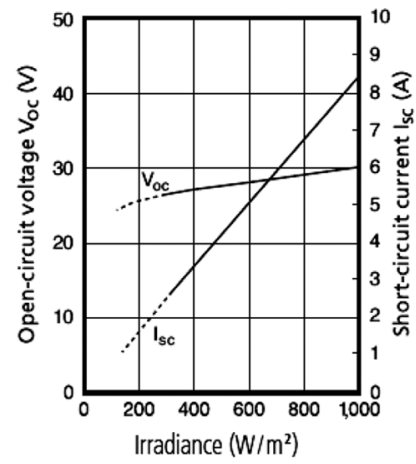

Fig. 1. (a) Example of the characteristic curves I-V, P-V, and (b) $V_{o c}-G$, $\mathrm{I}_{\mathrm{Sc}}-\mathrm{G}$ for a commercially available PV module of $180 \mathrm{~W}$.

An initial value for $\mathrm{I}_{\mathrm{MPP}}$ can be based on the assumption that $\mathrm{I}_{\mathrm{SC}}$ is approximately $5-15 \%$ greater than $\mathrm{I}_{\mathrm{MPP}}$. Thus

$$
I_{\mathrm{MPP}} \approx 0.9 \cdot I_{s c}(\mathrm{~A})
$$

and, finally, from (1)

$$
I_{\mathrm{MPP}} \approx 0.00759 \cdot G(\mathrm{~A})
$$

Furthermore, a $\mathrm{P}_{\mathrm{MPP}}-\mathrm{V}_{\mathrm{MPP}}$ curve can be graphically extracted from Fig. 1(a), where certain $P-V$ curves are given for various irradiance values. A linear function $\mathrm{P}_{\mathrm{MPP}}=\mathrm{aV}_{\mathrm{MPP}}+$ $\mathrm{b}$ can be assumed to connect the corresponding MPPs [dashed line in Fig. 1(a)]. For the subject module, this equation is

$$
P_{\mathrm{MPP}}=40 V_{\mathrm{MPP}}-770(\mathrm{~W}) .
$$

Since

$$
P_{\mathrm{MPP}}=V_{\mathrm{MPP}} \times I_{\mathrm{MPP}}(\mathrm{W})
$$

Then, from (4)-(6)

$$
V_{\mathrm{MPP}}=\frac{770}{40-0.00759 G}(\mathrm{~V}) .
$$

An approximate estimation of $\mathrm{I}_{\mathrm{sc}}, \mathrm{V}_{\mathrm{oc}}, \mathrm{I}_{\mathrm{MPP}}$, and $\mathrm{V}_{\mathrm{MPP}}$ for specified irradiance $G$ is possible with (1)-(7). Nevertheless, the values of $\mathrm{I}_{\mathrm{MPP}}$ and $\mathrm{V}_{\mathrm{MPP}}$ are recalculated in Section II-B in order to be corrected.

\section{B. Effective Solar-Cell Model}

Various models have been proposed for the mathematical simulation of a PV module. Among them, the so-called effective solar-cell model [25], [26], a version of the two-diode model, was chosen in the present study, as it is preferred for implementations where good accuracy is needed. This model introduces the fictitious component of the photovoltaic resistance $R_{P V}$, which incorporates the series and parallel resistances of the standard model and can take positive and negative values. 
Considering a typical I-V characteristic curve, given the values of the $\mathrm{I}_{\mathrm{sc}}, \mathrm{V}_{\mathrm{oc}}, \mathrm{V}_{\mathrm{MPP}}, \mathrm{I}_{\mathrm{MPP}}$, and the slope $\mathrm{M}$ at $\mathrm{V}_{\mathrm{oc}}$ $(\mathrm{M}=\mathrm{dV} / \mathrm{dI}$ for $\mathrm{I}=0)$, the following equations are valid for the effective solar-cell model, independent of the material, the properties, or the size of the solar cell [26]:

$$
\begin{aligned}
& M= \frac{V_{o c}}{I_{s c}}\left(-5.411 \frac{V_{\mathrm{MPP}} * I_{\mathrm{MPP}}}{V_{o c} * I_{s c}}+6.450 \frac{V_{\mathrm{MPP}}}{V_{o c}}\right. \\
&\left.\quad+3.417 \frac{I_{\mathrm{MPP}}}{I_{s c}}-4.422\right) \\
& R_{P V}=-M \frac{I_{s c}}{I_{\mathrm{MPP}}}+\frac{V_{\mathrm{MPP}}}{I_{M P P}}\left(1-\frac{I_{s c}}{I_{\mathrm{MPP}}}\right) \\
& V_{t}=-\left(M+R_{P V}\right) \cdot I_{s c} \\
& I_{p h}=I_{s c} \\
& I_{o}=I_{s c} \cdot e^{-\frac{V_{o c}}{V_{t}}} \\
& V=V_{t} \cdot \ln \left(\frac{I_{p h}-I+I_{o}}{I_{o}}\right)-I \cdot R_{P V} .
\end{aligned}
$$

Equations (8)-(13) can also be used for the determination of the respective values of a solar panel; thus, by using them with the aid of the expressions of Section II-A, an algorithm was developed in Visual C++. The algorithm takes as an input the irradiance $G$ and calculates $I_{s c}$ and $V_{o c}$ from (1) and (2). Then, for the points which lie in the following area:

$$
\begin{gathered}
0.75 \cdot V_{o c} \leq V_{M P P i} \leq 0.9 \cdot V_{o c} \\
0.7 \cdot I_{s c} \leq I_{\mathrm{MPPi}} \leq 0.95 \cdot I_{s c}
\end{gathered}
$$

an iterative process is applied in order to find the appropriate $\mathrm{V}_{\mathrm{MPPi}}$ and $\mathrm{I}_{\mathrm{MPPi}}$ values that, after executing (8)-(12), confirm (13). Thus, the method converges when, in (13), for $\mathrm{I}=\mathrm{I}_{\mathrm{MPPi}}$ the error $e=V\left(I_{\mathrm{MPPi}}\right)-V_{\mathrm{MPPi}}$ is minimized $\left(<10^{-5}\right)$. Finally, the algorithm compares and corrects the values of $\mathrm{V}_{\mathrm{MPP}}$ and $\mathrm{I}_{\mathrm{MPP}}$ as estimated in the graphical approach, (4) and (7).

\section{Simulation of the PV System in PSIM Software}

An integrated single-phase PV model was developed in PSIM, comprising the basic elements and control circuits of typical PV systems. A code file, written in Visual $\mathrm{C}++$ as described before, was implemented in a General DLL Block to represent the MPP tracker of the system. The main inputs of the model are the irradiance $\mathrm{G}\left(\right.$ in $\mathrm{W} / \mathrm{m}^{2}$ ) and the number of $\mathrm{PV}$ panels. It is assumed that the PV panels are series connected to a single-phase string inverter.

The DLL block tracks the MPP for a given irradiance and extracts two outputs: $I_{M P P}$ and $V_{M P P}^{\prime}$ that correspond to the string of panels. (Note: with $\mathrm{V}_{\mathrm{MPP}}^{\prime}$ and $\mathrm{P}_{\mathrm{MPP}}^{\prime}$, we now refer to the respective values of the string (i.e., the $\mathrm{V}_{\mathrm{MPP}}$ and $\mathrm{P}_{\mathrm{MPP}}$ extracted by the algorithm), multiplied with the number $n$ of panels forming the string).

The MPP tracker is modeled as a dc-dc boost converter, consisting of the input capacitance $\mathrm{C} 1$, the input inductor $\mathrm{L}$, switch $\mathrm{S} 1$, diode $\mathrm{D} 1$, and the output capacitance $\mathrm{C} 2$. The first role of the dc-dc converter is to impose the reference voltage $\mathrm{V}_{\mathrm{MPP}}^{\prime}$ on capacitor $\mathrm{C} 1$ and, thus, on the terminals of the PV panels. This is achieved by the first part of the control system shown in Fig. 2 where the error $V_{\text {in }}-V_{M P P}^{\prime}$ between the actual PV voltage $\left(V_{\text {in }}\right)$ and the reference voltage is passed through a PI controller and a limiter. This is the first input to summer $\Sigma$. The other input

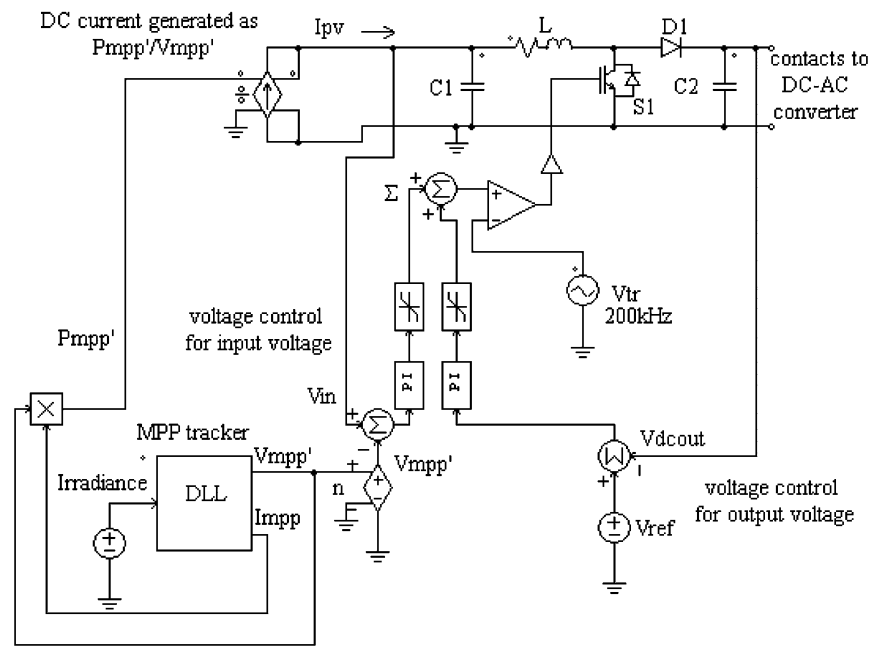

Fig. 2. MPP tracker and dc-dc boost converter.

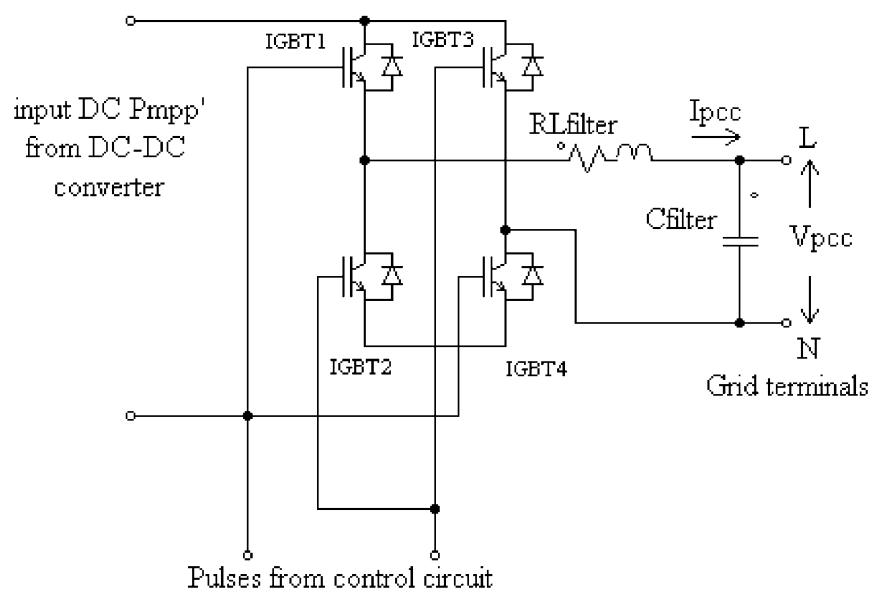

Fig. 3. Full-bridge switching dc-ac converter.

to $\Sigma$ is a signal that controls the output voltage $V_{\text {dcout }}$, of the dc-dc converter (i.e., the voltage across $\mathrm{C} 2$ which is the input to the dc-ac inverter. This voltage should be kept almost constant at a predefined value $V_{\text {ref }}$, depending on the size of the dc-ac inverter. The error $\mathrm{V}_{\text {ref }}-\mathrm{V}_{\text {dcout }}$ is passed through another PI controller and another limiter and is added with the signal that controls $V_{\text {in }}$. The output of $\Sigma$ is the final signal which, by comparison with the saw-type signal $\mathrm{V}_{\mathrm{tr}}$, generates the gating pulses on S1. It is assumed that the instantaneous power of the PV panels is equal to their maximum power for the given irradiance. For this reason, the PV panels were modeled as a current source $\left(\mathrm{I}_{\mathrm{PV}}\right)$, controlled by the instantaneous voltage $V_{\text {in }}$ so that $P_{M P P}^{\prime}=I_{P V} \times V_{\text {in }}$. When steady-state conditions are reached, $\mathrm{V}_{\text {in }}=\mathrm{V}_{\mathrm{MPP}}^{\prime}, \mathrm{I}_{\mathrm{PV}}=\mathrm{I}_{\mathrm{MPP}}$, and $\mathrm{V}_{\mathrm{dcout}}=\mathrm{V}_{\text {ref }}$.

$\mathrm{P}_{\mathrm{MPP}}^{\prime}$ from the dc-dc boost converter is then led to a dc-ac inverter modeled as a full-bridge switching converter (Fig. 3) [27], [28]. The converter is a voltage-source current-controlled one, as is the case with the majority of PV inverters. A low-pass filter at its output $\left(\mathrm{R}_{\text {filter }}, \mathrm{L}_{\text {filter }}, \mathrm{C}_{\text {filter }}\right)$ allows only the fundamental and some minor voltage harmonics to appear at the point of common coupling (PCC) with the grid. The aim of its control system is to produce an output current $\mathrm{I}_{\mathrm{PCC}}$, which: 1) is almost sinusoidal, 2) is in phase with the grid voltage $\mathrm{V}_{\mathrm{PCC}}$, at the $\mathrm{PCC}$ 


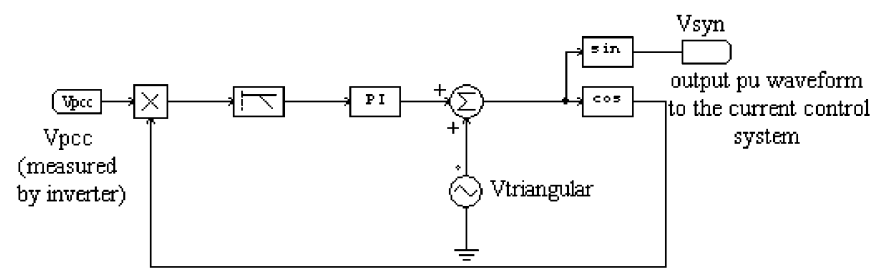

Fig. 4. Phase-locked loop system.

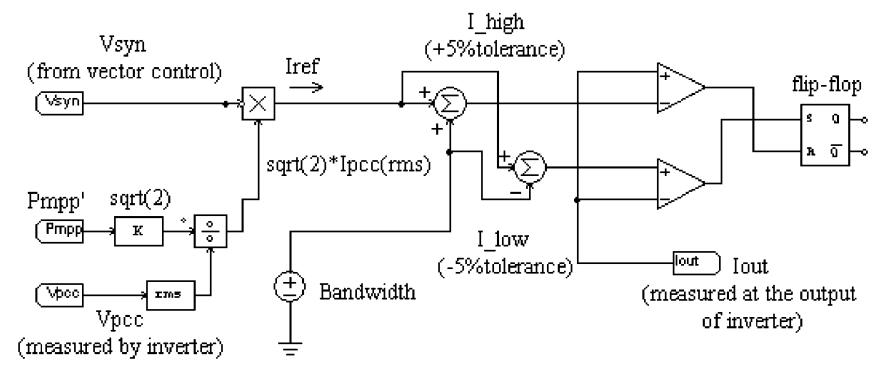

Fig. 5. Current control circuit.

and 3) has an rms value so that $\mathrm{P}_{\mathrm{MPP}}^{\prime}=\mathrm{V}_{\mathrm{PCC}(\mathrm{rms})} \times \mathrm{I}_{\mathrm{PCC}(\mathrm{rms})}$ (i.e., the converter transfers the dc power to the ac grid). The converter senses the instantaneous $\mathrm{V}_{\mathrm{PCC}}$ and calculates its rms value. The rms value of the reference output current is then calculated by $\mathrm{I}_{\mathrm{PCC}(\mathrm{rms})}=\mathrm{P}_{\mathrm{MPP}}^{\prime} / \mathrm{V}_{\mathrm{PCC}(\mathrm{rms})}$ The instantaneous grid voltage $V_{P C C}$ is passed through a phase-locked loop (PLL) system as shown in Fig. 4. The output of the PLL system $V_{\text {syn }}$ is a sinusoid with unity amplitude and in phase with the fundamental component of $\mathrm{V}_{\mathrm{PCC}}$. This sinusoid is then multiplied by $\sqrt{2} \cdot I_{P C C(r m s)}$ to form the instantaneous reference output current $I_{\text {ref }}$, as shown in Fig. 5.

The four switches (IGBT1-IGBT4 in Fig. 3) are controlled so that the instantaneous output current $\mathrm{I}_{\mathrm{PCC}}$ follows the reference current, $\mathrm{I}_{\mathrm{ref}}$ as closely as possible. To achieve this, a narrow band is formed around the instantaneous reference current. The upper limit of this band is called $\mathrm{I}_{\text {high }}$ and the lower limit is $\mathrm{I}_{\text {low }}$ (Fig. 5). When the instantaneous value of $\mathrm{I}_{\mathrm{PCC}}$ is larger than $\mathrm{I}_{\text {high }}$, switches IGBT3 and IGBT2 close while the other two open. When $\mathrm{I}_{\mathrm{PCC}}<\mathrm{I}_{\text {low }}$, the switch pairs reverse their state. If $\mathrm{I}_{\text {low }}<\mathrm{I}_{\mathrm{PCC}}<\mathrm{I}_{\text {high }}$, the state of the switches remains unchanged. A flip-flop is finally used to generate the gating pulses of the switches. The width of the band influences the switching frequency and the harmonic distortion of the output current. A very narrow band will create a large switching frequency (and, thus, large switching losses) and small current harmonic distortion. The width of the band is selected to be constant and equal to $\pm 5 \%$ of the peak value of the nominal inverter current. In this case, the total harmonic distortion (THD) of the nominal output current is less than 3\% (as shown in the next section) and the switching losses are kept low. When, however, the inverter operates at currents lower than the nominal, the $\mathrm{THD}_{\mathrm{I}}$ increases.

Fig. 6 shows the dc output of the panels and the final ac outcome of the integrated PV model for one period. The power factor is close to unity; in this example, it is 0.953 . The generated dc power is $4.541 \mathrm{~kW}$, whereas the output ac power is approximately $4.378 \mathrm{~kW}$. It is obvious that the conversion has succeeded with limited losses.
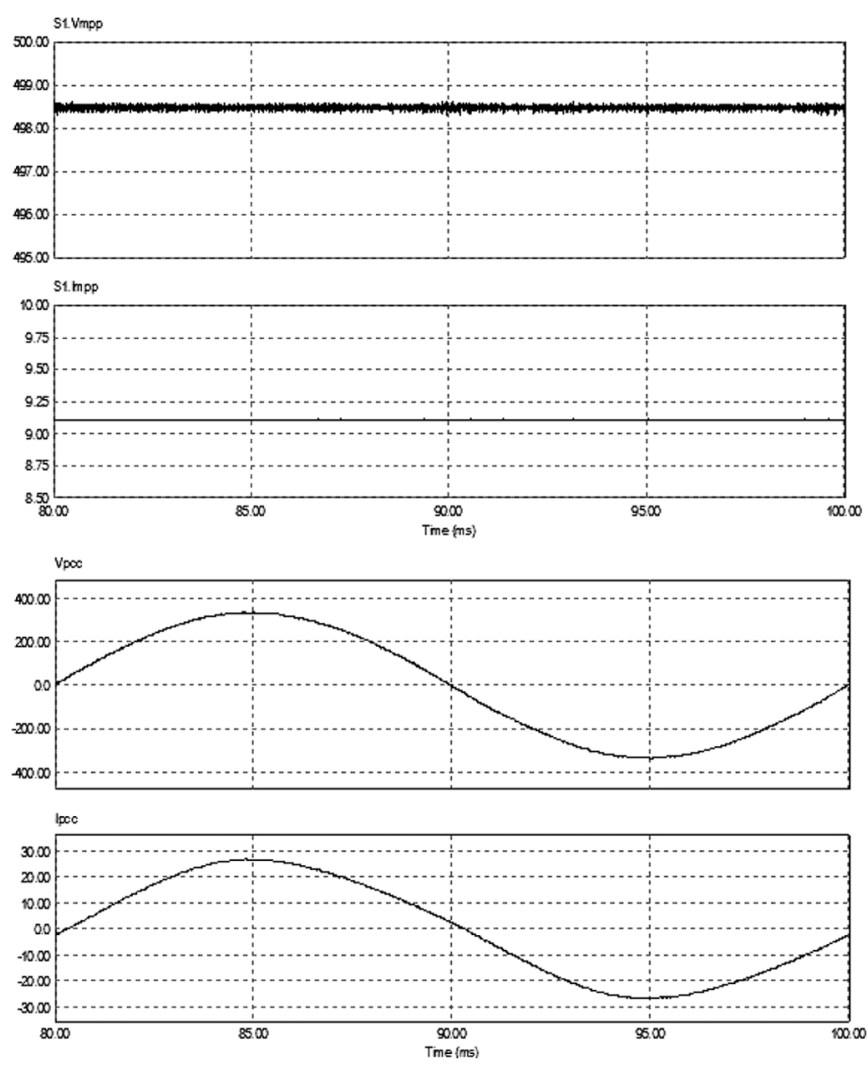

Fig. 6. DC output of the panels and the respective ac output of the PV system.

\section{VALIDATION OF THE INTEGRATED PV MODEL}

\section{A. Validation With Results From the Measurement Campaign}

The PV station studied is a $20-\mathrm{kWp}$ system situated in Korinos, Northern Greece. The station has been operating since Summer 2007 and is directly connected to an LV distribution feeder. The PV station is connected to the LV grid through three identical single-phase dc-ac converters, each rated at $5 \mathrm{~kW}$, $230 \mathrm{~V}, 21.8 \mathrm{~A}$ at the ac side. The harmonic impact of the station has been recorded for different weather conditions. At the beginning of the measuring campaign, the PV station was disconnected in order to track and register the background distortion of the network [29]. Data were acquired at two points: 1) the MV/ LV transformer which supplies the line and 2) the PCC (points 1 and 2 in Fig. 7). Two Fluke 1760 instruments were installed at points 1 and 2 with a sampling frequency of 10.24 $\mathrm{kHz}$. In general, the measurement of voltage and current harmonics belongs to Class I in compliance with the IEC 61000-47:2002 standard. Specifically, the maximum measurement error is $0.1 \%$ for voltage, $0.5 \%$ for current, and $0.5^{\circ}$ for phase. The harmonic measurement accuracy is $2 \%$ for voltage (up to the 31 st harmonic), $3 \%$ for current (up to the 31 st harmonic), and $2^{\circ}$ for phase. The PV plant is connected to a $150-\mathrm{kVA}, 20 / 0.4-\mathrm{kV}$ transformer via a $300-\mathrm{m}$ overhead line with the following parameters: $\mathrm{R}^{\prime}=1.268 \Omega / \mathrm{km}$ and $\mathrm{X}^{\prime}=0.422 \Omega / \mathrm{km}$ (data given by the Greek grid operator).

Fig. 8 depicts a daily curve of the fundamental and the harmonic currents at the output of one of the three identical dc-ac 


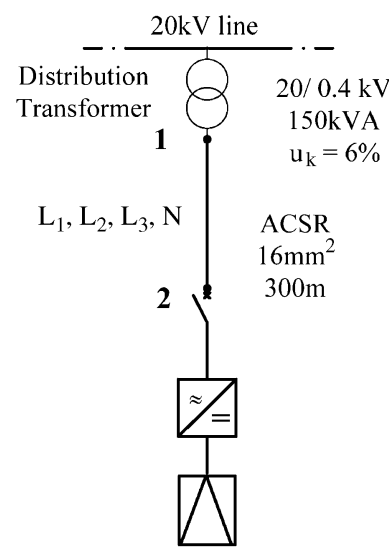

Fig. 7. Single-line diagram of the measured feeder.

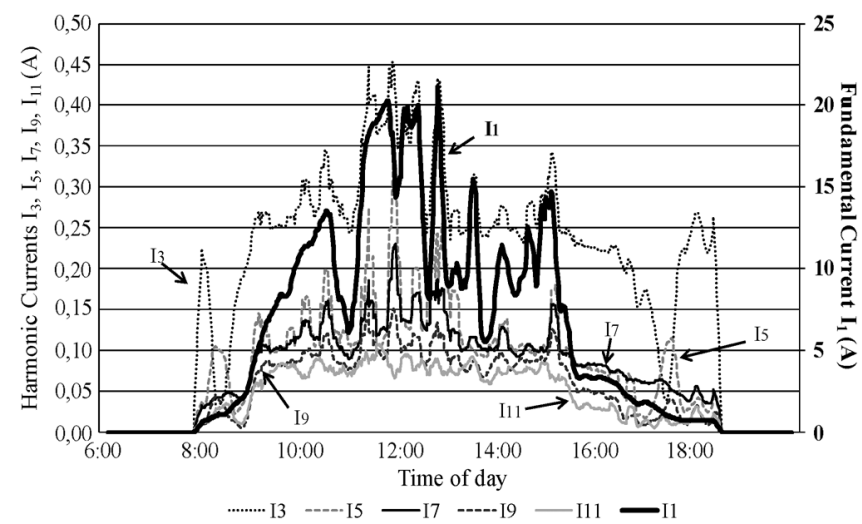

Fig. 8. Fundamental current and 3rd, 5th, 7th, 9th, and 11th order of current harmonics acquired in one day with the PV station in operation.

converters with the PV plant connected. The 3rd harmonic current presents intense peaks during sunrise and sunset, reaching approximately $40-50 \%$ of the amplitude of the fundamental current.

In order to validate our model correctly, the network where the PV plant is connected should also be modeled. This model was simulated with the data acquired from the measurement campaign. The secondary voltage of the transformer is simulated as a voltage source. The 5th and 7th order of voltage harmonics were recorded when the PV plant did not produce power or when it was disconnected. These harmonics, which represent the background harmonic pollution, are simulated with voltage sources [30], [31] in the 5th and 7th order. Their amplitude is determined through a "test and trial" process in order to give the same values of the voltage at the PCC as the ones acquired in the measurement with the switches of the PV plant off. Finally, when the PV plant was put out of operation, no load demand at the LV feeder was recorded, which means that the PV plant is the only installation connected in the particular line.

Fig. 9 depicts the simulated model of the network, with the PV plant model connected to it as a subcircuit. Table I provides some representative results from the validation of the network and the PV model. The values are average data for a one-hour interval with irradiance $1000 \mathrm{~W} / \mathrm{m}^{2}$. The harmonic content of the injected PV current was also measured and compared with the aforementioned PV-network model.

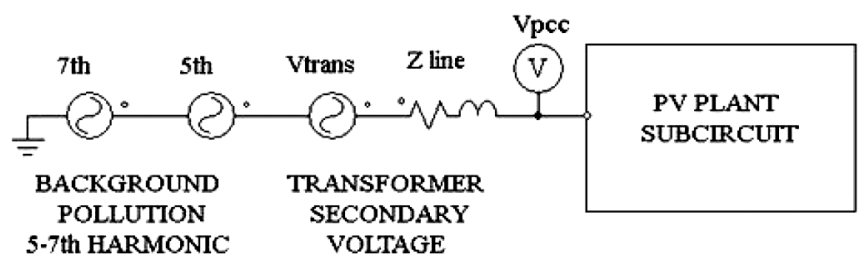

Fig. 9. Simulated model for validation with measurements.

TABLE I

COMPARISON OF THE SIMULATION RESUlTS

\begin{tabular}{c|c|c}
\hline \multicolumn{3}{|c}{ Validation of the Network Model (without PV) } \\
\hline $\begin{array}{c}\text { Harmonic } \\
\text { Order }\end{array}$ & $\begin{array}{c}\text { Voltage at PCC V } \\
\text { (PSIM) }\end{array}$ & $\begin{array}{c}\text { Voltage at PCC V rms } \\
\text { (Measurements) }\end{array}$ \\
\hline 1 & 232.00 & 229.82 \\
\hline 5 & 1.07 & 0.99 \\
\hline 7 & 0.70 & 0.66 \\
\hline THDV (\%) & 0.55 & 0.52 \\
\hline \multicolumn{3}{|c|}{ Validation of the PV Model } \\
\hline Harmonic & Voltage at PCC V & Voltage at PCC V \\
Order & (PSIM) & 234.04 \\
\hline 1 & 235.81 & 0.98 \\
\hline 3 & 1.67 & 1.26 \\
\hline 5 & 1.02 & 0.70 \\
\hline 7 & 0.76 & 0.75 \\
\hline THDV (\%) & 1.21 & \\
\hline & &
\end{tabular}

In Fig. 10, measured values of $\mathrm{THD}_{\mathrm{I}}$ covering a period of one day are presented along with simulated results. Harmonic distortion is a function of the per unit (p.u.) output power of the single-phase dc-ac converter $(5 \mathrm{~kW})$. In the simulation model, the width of the current band (see Fig. 5) was set at $1 \mathrm{~A}$ $( \pm 5 \% \times 21.8 \mathrm{~A})$ while the switching frequency was held constant at $7 \mathrm{kHz}$ for the whole operating range. It can be observed that the accuracy of the model is very good when the output power of the inverter is larger than $40 \%$ of its nominal power. The accuracy decreases at smaller power levels because the real dc-ac converters usually reduce their switching frequency at low power in order to reduce the switching losses. This action, however, increases the $\mathrm{THD}_{\mathrm{I}}$. Since, at low power, the harmonic currents are very small (in the order of milliamperes for a dc-ac converter rated at $5 \mathrm{~kW}$ ), the lower $\mathrm{THD}_{\mathrm{I}}$ introduced by the proposed model does not significantly affect the harmonic distortion of the voltage at the PCC. It is also evident from the amplitudes of voltage and current shown in Table I and Fig. 10 that the small measurement error introduced by the measuring instruments does not affect the validation of the model.

\section{B. Validation With Published Results}

Along with the measurement campaign, the PV model was also evaluated with laboratory tests. In the literature, one can find numerous field measurements referring to harmonic emissions of grid-connected photovoltaic systems [32]-[37]. In these studies, the dependency of the harmonic spectrum on the solar capacity and the size of the PV system are widely remarked. 


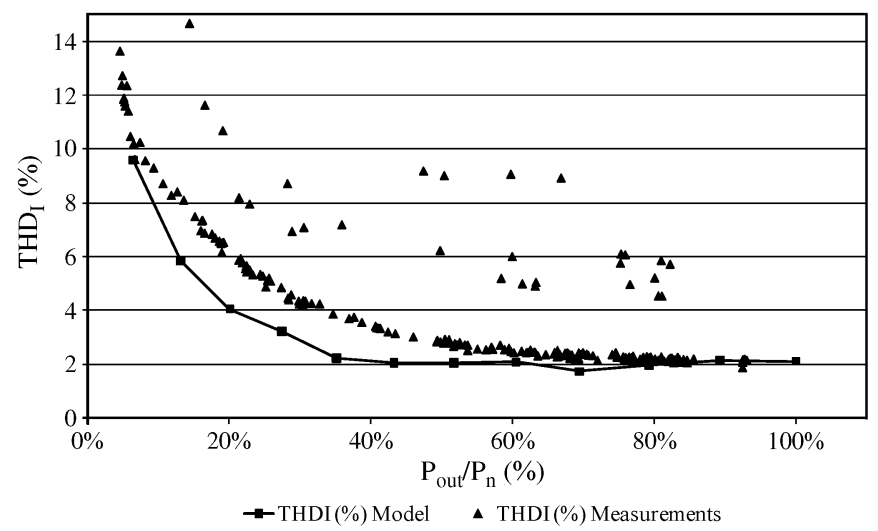

Fig. 10. Measured and simulated values of THDI (\%).

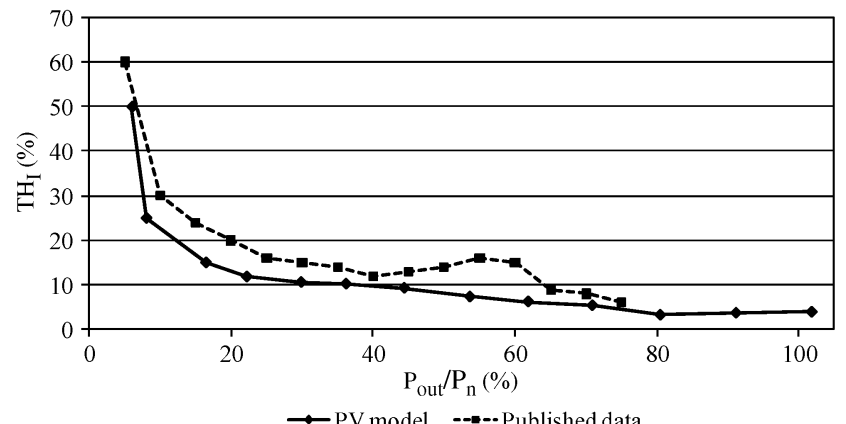

Fig. 11. THDI of the simulated model versus per-unit output power $(0.85 \mathrm{~kW}$ inverter) and respective published data.

TABLE II

COMPARISON OF THE SIMULATION RESUlTS

\begin{tabular}{l|c|c|c}
\hline \multirow{2}{*}{$\begin{array}{c}\text { Laboratories tests } \\
\text { [Schlabbach] }\end{array}$} & Power (\% of rated power) & $10 \% \ldots 25 \%$ & $>25 \%$ \\
\cline { 2 - 4 } & $\mathrm{THD}_{\mathrm{I}}$ & $20 \ldots 30 \%$ & $<5 \%$ \\
\hline $\begin{array}{c}\text { Simulation results } \\
\text { (PV model) }\end{array}$ & Power (\% of rated power) & $10 \% \ldots 25 \%$ & $>25 \%$ \\
\cline { 2 - 4 } & $\mathrm{THD}_{\mathrm{I}}$ & $25 \ldots 12 \%$ & $<10 \%$ \\
\hline
\end{tabular}

A small PV system of $0.85 \mathrm{~kW}$ was simulated and the harmonic behavior of the inverter was compared with corresponding laboratory results found in the literature [37]. Fig. 11 depicts the $\mathrm{THD}_{\mathrm{I}}$ of the PV model's output current compared with [37, Fig. 5], whereas in Table II, the results of our simulation with the aforementioned study of Schlabbach et al. are well verified.

\section{Penetration Scenarios}

The penetration level $\mathrm{p}$ is defined as the ratio of the total installed PV capacity to the nominal power $\mathrm{S}_{\mathrm{N} \text {,transf }}$ of the feeder transformer

$$
p=\left(\sum_{i=1}^{n} P_{P V, i}^{\text {installed }}\right) / S_{N, \text { transf }} .
$$

In order to examine PV penetration depths as well as the influence of PV siting in the voltage and harmonic profile of an LV feeder, the validated model has been applied to three different topologies, simulating various PV capacities.

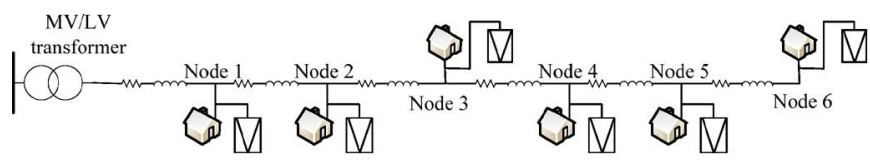

Fig. 12. LV network with dispersed loads and PV units.

TABLE III

SITING OF PV UNITS

\begin{tabular}{c|c|c|c|c|c|c}
\hline \multirow{2}{*}{ Scenario } & \multicolumn{7}{|c}{ PV capacity in each node $(\mathrm{kW} / \mathrm{ph})$} \\
\cline { 2 - 7 } & Node1 & Node2 & Node3 & Node4 & Node5 & Node6 \\
\hline 0 & 15.8 & 0 & 0 & 0 & 0 & 0.0 \\
\hline 1 & 2.6 & 2.6 & 2.6 & 2.6 & 2.6 & 2.6 \\
\hline 2 & 0 & 2.6 & 2.6 & 2.6 & 2.6 & 5.2 \\
\hline 3 & 0 & 0 & 2.6 & 2.6 & 2.6 & 7.8 \\
\hline 4 & 0 & 0 & 0 & 2.6 & 2.6 & 10.5 \\
\hline 5 & 0 & 0 & 0 & 0 & 2.6 & 13.2 \\
\hline 6 & 0 & 0 & 0 & 0 & 0 & 15.8 \\
\hline
\end{tabular}

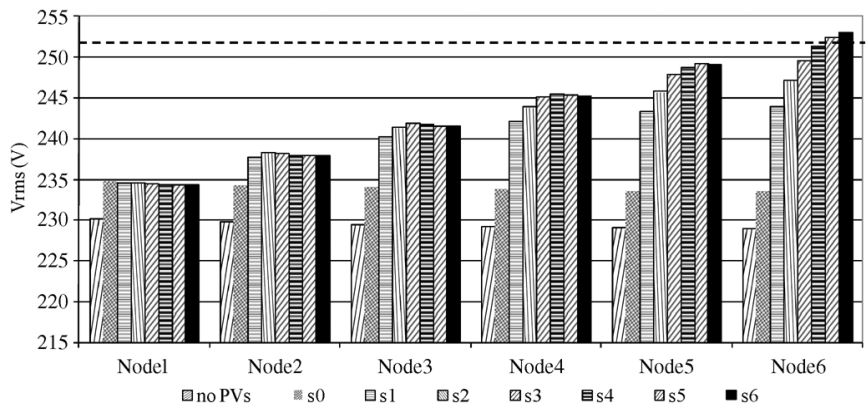

Fig. 13. Voltage at the nodes for scenarios 0-6.

\section{A. Scenarios in an LV Network with Aggregated PV Capacity at the end of the Line}

An investigation was conducted with scenarios including a radial LV feeder with dispersed residential loads and PV units. The LV network consists of a three-phase overhead line with $\mathrm{R}^{\prime}=1.268 \Omega / \mathrm{km}$ and $\mathrm{X}^{\prime}=0.422 \Omega / \mathrm{km}$ and a $250-\mathrm{kVA}$, 20/0.4-kV transformer. Residential loads $\mathrm{P}_{\text {load }}$ were assumed to be equal to $200 \mathrm{~W} / \mathrm{ph}$ with $\cos \varphi=0.6$ (inductive), which is the worst case of low load demand. The distance between the nodes was considered to be $50 \mathrm{~m}$. There were various scenarios examined with different topologies of the PV units, PV capacities, and topologies. In the first group of scenarios, a sixnode LV network was examined with a load connected in each node (Fig. 12). The siting of the PV units differed, as shown in Table III. The sum of the PV capacity ( $p=18.96 \%$ is approximately the same for the seven scenarios; thus, only the topology differs.

In addition, a scenario assuming that no PV units connected was executed. Fig. 13 shows the voltage at all nodes and for all scenarios. The dashed line presents the voltage limit $(253 \mathrm{~V})$; thus, violation was noticed for scenarios 5 and 6 , at the 6th node, showing that an overvoltage issue occurs as the PV capacity increases at the end of the LV line.

Respective scenarios, as shown in Table III, were executed by doubling the PV capacity at each node $(p=37.92 \%)$. Fig. 14 presents the corresponding results, where it is obvious that from 


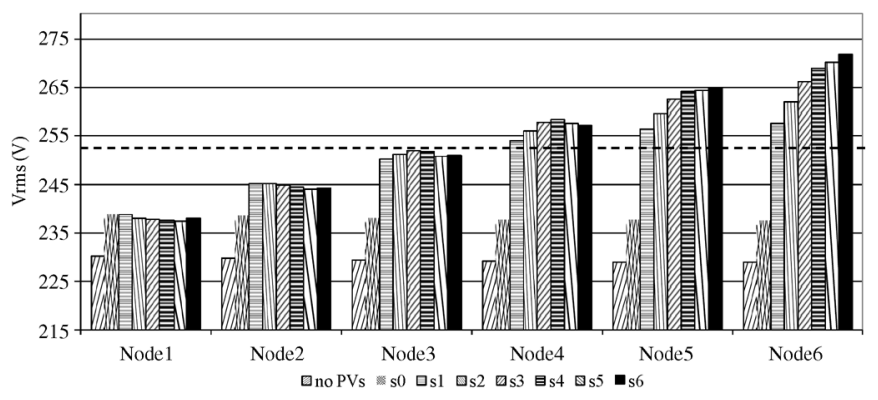

Fig. 14. Voltage at the nodes for scenarios 0-6 with doubled PV capacity.

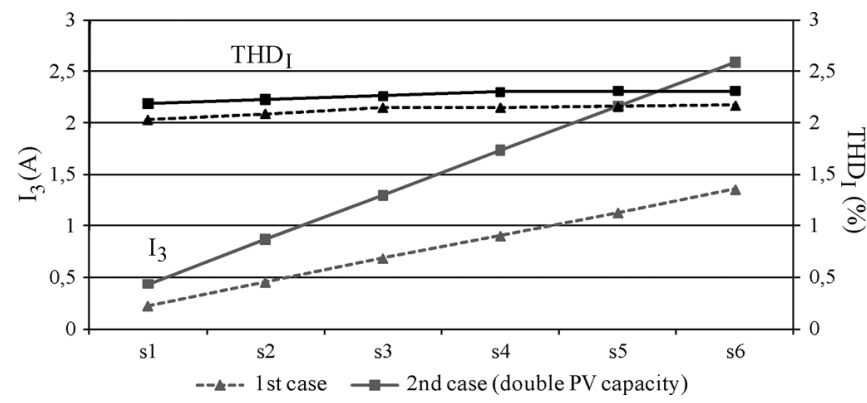

Fig. 15. $I_{3}$ and $T H D_{I}$ at node 6 for all scenarios and cases.

the 4th node and beyond, there is a violation of the voltage limit (shown with the dashed line) which occurs even from the first scenario.

Harmonic issues were also studied. The values of $\mathrm{I}_{3}$ (in amps), presented in Fig. 15 for node 6, are proportional to the increased PV capacity. Yet, the $\mathrm{I}_{3}$ as a ratio of the total produced current is almost stable. This is shown in the $\mathrm{THD}_{\mathrm{I}}$ curves presented in the same figure, where distortion slightly rises with PV capacity. The rise is also insignificant for the case of double PV capacity and still within the limits. Also, in all scenarios, voltage harmonic distortion $\mathrm{THD}_{\mathrm{V}}$ at all nodes was less than $1.5 \%$, assuming the voltage at the MV side of the distribution transformer was to be purely sinusoidal. The limits on harmonic distortion are set by national and international standards [1], [2]. According to the guidelines issued by the Greek grid operator, $\mathrm{THD}_{\mathrm{I}}$ of PV inverters should be less than $5 \%$. $\mathrm{THD}_{\mathrm{V}}$ at each node should be less than $8 \%$ [1]. According to [2], the total rated-current distortion $\left(\mathrm{TRD}_{\mathrm{I}}\right)$ at the PCC should be less than $5 \%$. Since in the scenarios examined, the PV inverters were assumed to operate at their nominal power, $\mathrm{TRD}_{\mathrm{I}}=\mathrm{THD}_{\mathrm{I}}$. Thus, the calculated harmonic distortion in all scenarios falls within the limits, specified in the aforementioned standards.

\section{B. Scenarios in the LV Network With Uniform PV Capacity Along the Line}

Further scenarios were studied assuming the topology of Fig. 11, where PV units are located uniformly along the feeder. Basically, the scenarios are relevant to scenario 1 of Section IV-A. However, increasing the capacity of the PV units was considered, as presented in Table IV. The scope of the study was to find the highest penetration level of PV units in a radial network of six nodes. The configuration of the feeder (loads, distances, and line) remained the same as previous.

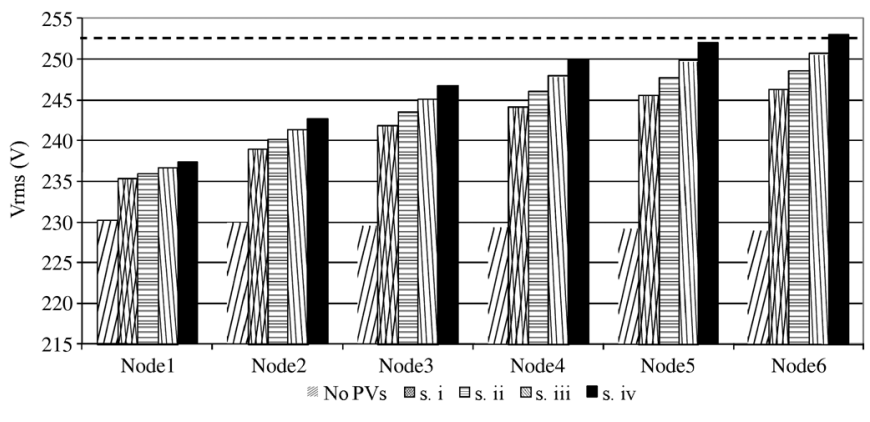

Fig. 16. Voltage at the nodes for scenarios i-iv.

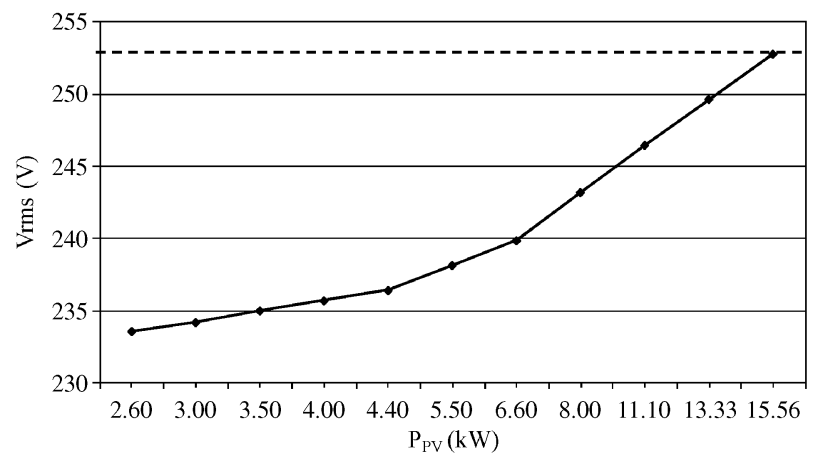

Fig. 17. Voltage at node 6 when increasing PV capacity.

TABLE IV

CAPACITY OF PV UNITS

\begin{tabular}{c|c|c|c|c|c|c|c}
\hline \multirow{2}{*}{ Scenario } & \multicolumn{7}{|c}{ PV capacity in each node (kW/ph) } \\
\cline { 2 - 8 } & Node1 & Node2 & Node3 & Node4 & Node5 & Node6 & Total \\
\hline i & 3.1 & 3.1 & 3.1 & 3.1 & 3.1 & 3.1 & 18.6 \\
\hline ii & 3.5 & 3.5 & 3.5 & 3.5 & 3.5 & 3.5 & 21.0 \\
\hline iii & 4.0 & 4.0 & 4.0 & 4.0 & 4.0 & 4.0 & 24.0 \\
\hline iv & 4.4 & 4.4 & 4.4 & 4.4 & 4.4 & 4.4 & 26.4 \\
\hline
\end{tabular}

Fig. 16 shows the voltage at all nodes and for all of the examined scenarios, until the voltage limit is violated. This occurred at scenario iv, where the PV capacity of $4.4 \mathrm{~kW} /$ phase was installed at each node $(p=31.68 \%)$; the violation was observed at the most distant node. A further increase of PV capacity would gradually cause voltage-limit violations in the other nodes as well. The $\mathrm{THD}_{\mathrm{V}}$ and $\mathrm{THD}_{\mathrm{I}}$ were within the limits specified in [1] and [2] in all of the aforementioned scenarios.

\section{Scenarios in the LV Network With Increasing PV Capacity at the End of the Line}

Assuming scenario 6 (Section IV-A), an investigation followed in order to assign the highest PV capacity that can be installed, in compliance with the standard rules. In addition, the aggregation of PV units in the end of a line, which is obviously the worst case, will show the impact of PV concentration with respect to the uniform sitings of PV units. The voltage profile at node 6 for increasing the PV capacity is presented in Fig. 17. The voltage reaches the limit for PV capacity of $15.56 \mathrm{~kW} / \mathrm{ph}$ ( $p=18.67 \%$ ); in case of a uniform topology, the penetration ability would be approximately $70 \%$ higher, that is, $26.4 \mathrm{~kW} / \mathrm{ph}$ (Table IV). 
In all scenarios examined, it was assumed that the taps of the distribution transformer remain unchanged to the position they had without any PV system. One could argue that by changing the transformer taps, the voltage rise could be within the specified limits. However, such an action could lead the feeder voltage to fall below the lower limit (e.g., if the weather becomes suddenly cloudy). Since the automatic tap-changing mechanism does not apply to distribution transformers, the tap-changing option cannot be used.

\section{CONCLUSION}

In this paper, extensive work has been presented regarding issues of PV modeling and penetration to the network. An integrated model was developed according to the features of PV panels and inverters. An MPP tracking algorithm was designed, based on the mathematical functions and characteristic curves of PV panels and inserted in the model. Voltage and harmonic behavior of the PV system were then validated with data acquired from field measurements and published results.

Simulations were performed in order to investigate the influence of PV generation on PQ. A typical radial LV distribution feeder with loads and PV units dispersed in six nodes was studied. The simulation results showed that even small PV penetration $(\sim 18 \%)$ can cause violations of voltage limits, especially at the nodes which are distant from the transformer. Harmonic issues were also studied for various topologies and penetration levels. However, no violation of harmonic limits was detected.

It is obvious that as the concentration of PV units increases in the LV network, problems will be inevitable. There are many technical aspects that engineers should consider, such as the large voltage fluctuations (flicker) due to rapid irradiation changes, protection systems' regulation with respect to possible reverse power-flow conditions, etc. Violation of the upper voltage threshold is one of the PQ issues to be encountered. $\mathrm{PV}$ inverters are calibrated to disconnect the unit when the voltage at the PCC exceeds $1.1 \mathrm{~V}_{\mathrm{n}}$ (i.e., $253 \mathrm{~V}$ ). So PV units will occasionally have to be shut down. Thus, a compromise of PV expansion should be made, taking into account parameters, such as penetration level, network topology, and load profiles.

The model developed within our work is a useful tool for research regarding voltage levels and harmonic distortion. It incorporates the properties of PV systems of various types and sizes and provides an accurate and safe simulation of the realistic behavior of PV units under different circumstances of installed capacity, irradiance, and temperature. In this respect, load flow and harmonic analysis can be performed using a unified model instead of $\mathrm{P}-\mathrm{Q}$ elements or current sources. The user only assigns the type and number of PV panels in order to define PV capacity as well as the solar radiation, in order to determine operational conditions, such as output power and harmonic behavior of the PV system under study.

\section{REFERENCES}

[1] Voltage Characteristics of Electricity Supplied by Public Distribution System, Standard EN 50160, 2004.

[2] IEEE Standard for Interconnecting Distributed Resources With Electric Power Systems, IEEE Std. IEEE-1547, 2003.
[3] V. H. Méndez Quezada, J. R. Abbad, and T. Gómez San Román, “Assessment of energy distribution losses for increasing penetration of distributed generation," IEEE Trans. Power Syst., vol. 21, no. 2, pp. 533-540, May 2006.

[4] C. Mayr, R. Bründlinger, and B. Bletterie, "Photovoltaic-inverters as active filters to improve power quality in the grid. What can state-ofthe-art equipment achieve?," presented at the 9th Int. Conf. Electrical Power Quality and Utilization, Barcelona, Spain, Oct. 2007.

[5] C. Schwaegerl, M. H. J. Bollen, K. Karoui, and A. Yagmur, "Voltage control in distribution systems as a limitation of hosting capacity for distributed resources," presented at the 18th Int. Conf. Electricity Distribution, Turin, Italy, Jun. 2005.

[6] W. El-Khattam, Y. G. Hegazy, and M. M. A. Salama, "Investigating distributed generation systems performance using Monte Carlo simulation," IEEE Trans. Power Syst., vol. 21, no. 2, pp. 524-532, May 2006.

[7] P. Denholma and R. M. Margolis, "Evaluating the limits of solar photovoltaic (PV) in traditional electric power systems," Elsevier, Energy Policy, vol. 35, pp. 2852-2861, 2007.

[8] V. Van Thong, D. Van Dommelen, J. Driesen, and R. Belmans, "Using dynamic simulation to study the penetration level of distributed energy resources," in Proc. Power Tech, St. Petersburg, Russia, Jun. 2005, pp. $1-6$.

[9] F. Katiraei, K. Mauch, and L. Dignard-Bailey, "Integration of photovoltaic power systems in high penetration clusters for distribution networks and mini-grids," Int. J. Distrib. Energy Resources, vol. 3, no. 3, pp. 207-223, Nov. 2006.

[10] T. Ackermann and V. Knyazkin, "Interaction between distributed generation and the distribution network: Operation aspects," in Proc. IEEE Power Eng. Soc. Asia Pacific Transmission and Distribution Conf. Exhibit., Oct. 2002, vol. 2, pp. 1357-1362.

[11] A. Bhowmik, A. Maitra, S. M. Halpin, and J. E. Schatz, "Determination of allowable penetration levels of distributed generation resources based on harmonic limit considerations," IEEE Trans. Power Del., vol. 18, no. 2, pp. 619-624, Apr. 2003.

[12] S. J. Ranade and W. Xu, "An overview of harmonics modeling and simulation," Elect. Power Syst. Res., vol. 74, pp. 37-56, Apr. 2005.

[13] IEEE Recommended Practices and Requirements for Harmonic Control in Electrical Power Systems, IEEE Std. 519-1992, Jun. 2004.

[14] A. Canova, L. Giaccone, F. Spertino, and M. Tartaglia, "Electrical impact of photovoltaic plant in distributed network," IEEE Trans. Ind. Appl., vol. 45, no. 1, pp. 341-347, Jan./Feb. 2009.

[15] Y. Yuan, K. Qian, and C. Zhou, "The optimal location and penetration level of distributed generation," in Proc. UPEC, Brighton, U.K., Sep. 2007, pp. 917-923.

[16] A. Gross, J. Bogenspenger, and D. Thyr, "Impacts of large scale penetration systems on the low voltage network," Solar Energy, vol. 59, no. 4-6, pp. 143-149, 1997.

[17] "Impacts of power penetration from photovoltaic power systems in distribution networks," Frederica, Denmark, Report IEA PVPS T5-10, 2002. [Online]. Available: www.iea.org

[18] S. Favuzza, F. Spertino, G. Gratiti, and G. Vitale, "Comparison of power quality impact of different photovoltaic inverters: The viewpoint of the grid," in Proc. IEEE Int. Conf. Industrial Technology, Dec. 2004, pp. 542-547.

[19] T. Senjyu, H. Takara, K. Uezato, T. Funabashi, and T. Ito, "Loadfollowing control for dispersed generators using a PI controller, electrical," Eng. Jpn., vol. 145, no. 2, 2003, Translated from Denki Gakkai Ronbunshi, Vol. 122-C, No. 8, pp. 1333-1340, Aug. 2002.

[20] S. Yuvarajan, D. Yu, and S. Xub, "A novel power converter for photovoltaic applications," J. Power Sources, vol. 135, pp. 327-331, 2004.

[21] M. Veerachary, T. Senjyu, and K. Uezato, "Voltage-based maximum power point tracking control of PV system," IEEE Trans. Airspace Electron. Syst., vol. 38, no. 1, pp. 262-270, Jan. 2002.

[22] S. Jain and V. Agarwal, "New current control based MPPT technique for single stage grid connected PV systems," Energy Convers. Manage., vol. 48, pp. 625-644, 2007.

[23] D. P. Hohm and M. E. Ropp, "Comparative study of maximum power point tracking algorithms," in Progress in Photovoltaics: Research and Applications. Hoboken, NJ: Wiley, Nov. 2002, pp. 47-62.

[24] S. Jain and V. Agarwal, "New current control based MPPT technique for single stage grid connected PV systems," Energy Convers. Manage., vol. 48, pp. 625-644, 2007. 
[25] G. Kunz and A. Wagner, "Internal series resistance determined of only one I-V curve under illumination," presented at the 19th Photovoltaic Energy Conf., Paris, France, 2004.

[26] C. Bendel and A. Wagner, "Photovoltaic measurement relevant to the energy yield," in Proc. World Conf. Photovoltaic Energy Conversion, Osaka, Japan, May 2003, pp. 1-4.

[27] A. F. Povlsen, "Distributed power using PV: Challenges for the grid," Renew. Energy World, vol. 6, no. 2, pp. 62-73, Mar./Apr. 2003.

[28] K.-H. Chaoa, S.-H. Hob, and M.-H. Wang, "Modeling and fault diagnosis of a photovoltaic system," Elect. Power Syst. Res., vol. 78, pp. 97-105, 2008.

[29] C. Collombet, J. M. Lupin, and J. Schonek, "Harmonic disturbances in networks and their treatment," Cahier Technique no. 152, Schneider Electric, 1999.

[30] Task Force on Harmonics Modeling and Simulation, "The modeling and simulation of the propagation of harmonics in electric power networks Part I: Concepts, model and simulation techniques," IEEE Trans. Power Del., vol. 11, no. 1, pp. 452-465, Jan. 1996, .

[31] Task Force on Harmonics Modeling and Simulation, "The modeling and simulation of the propagation of harmonics in electric power networks Part II : Samples systems and Examples," IEEE Trans. Power Del., vol. 11, no. 1, pp. 466-474, Jan. 1996.

[32] F. Batrinu, G. Chicco, J. Schlabbach, and F. Spertino, "Impacts of grid-connected photovoltaic plant operation on the harmonic distortion," in Proc. IEEE Mediterranean Electrotech. Conf., Malaga, Spain, May 2006, pp. 861-864.

[33] G. Chicco, J. Schlabbach, and F. Spertino, "Characterisation and assessment of the harmonic emission of grid-connected photovoltaic systems," in Proc. IEEE Power Tech, St. Petersburg, Russia, Jun. 2005, pp. $1-7$.

[34] G. Chicco, J. Schlabbach, and F. Spertino, "Experimental assessment of the waveform distortion in grid-connected photovoltaic installations," Solar Energy, vol. 83, no. 7, pp. 1026-1039, Jul. 2009.

[35] J. Schlabbach and A. Gross, "Harmonic current emission of photovoltaic inverters," presented at the 19th Int. Conf. Electricity Distribution, Vienna, Austria, May 2007.

[36] G. Chicco, L. Giaccone, F. Spertino, and G. Graditi, "Experimental methods to evaluate the impact of a photovoltaic system at the point of common coupling in low voltage networks," in Proc. SPEEDAM, Int. Symp. Power Electronics, Electrical Drives, Automation and Motion, Taormina, Italy, May 2006, pp. 537-541.

[37] J. Schlabbach, "Harmonic current emission of photovoltaic installations under system conditions," in Proc. 5th Int. Conf. European Electricity Markets, Lisbon, Portugal, May 2008, pp. 1-5.

[38] W. H. Kersting, "Radial distribution test feeders," IEEE Trans. Power Syst., vol. 6, no. 3, pp. 975-985, Aug. 1991.
Ioulia T. Papaioannou was born in 1980. She received the Dipl. Eng. and Ph.D. degrees in electrical and computer engineering from the Aristotle University of Thessaloniki, Thessaloniki. Greece, in 2004 and 2010, respectively.

Currently, she is a Researcher with the Institute for Energy in the Joint Research Centre of the European Commission. Her topics of research include distributed energy resources, power electronics, and energy markets integration.

Minas C. Alexiadis was born in 1969. He received the Dipl. Eng. and Ph.D. degrees in electrical and computer engineering from the Aristotle University of Thessaloniki, Thessaloniki, Greece, in 1994 and 2003, respectively .

Currently, he is a Lecturer with the Power System Laboratory at the Aristotle University of Thessaloniki. His research focuses on the fields of renewable energy sources, distributed generation, and artificial-intelligence applications in power systems.

Charis S. Demoulias (M'96) was born in 1961. He received the Dipl. and Ph.D. degrees in electrical engineering from the Aristotle University of Thessaloniki, Thessaloniki, Greece, in 1984 and 1991, respectively.

Currently, he is a Lecturer with the Electrical Machines Laboratory, Department of Electrical and Computer Engineering, Aristotle University of Thessaloniki. His research interests are in the fields of power electronics, harmonics, electric motion systems, and renewable energy sources.

Dimitris P. Labridis (SM'00) was born in 1958. He received the Dipl.-Eng. and Ph.D. degrees in electrical engineering from the Aristotle University of Thessaloniki, Thessaloniki, Greece, in 1981 and 1989, respectively.

Since 1986, he has been with the Electrical Engineering Department, Aristotle University of Thessaloniki, Thessaloniki, Greece, where he is currently a Professor. His research interests are power system analysis with a special emphasis on the simulation of transmission and distribution systems.

Petros S. Dokopoulos was born in 1939. He received the Dipl.Eng. degree from the Technical University of Athens, Athens, Greece, in 1962 and the Ph.D. degree from the University of Brunswick, Germany, in 1967.

Since 1978, he has been Full Professor in the Department of Electrical Engineering, Aristotle University of Thessaloniki, Thessaloniki, Greece, where he is currently Professor Emeritus. His research interests are dielectrics, power switches, generators, power cables, alternative energy sources, transmission, distribution, and fusion 